\title{
HOBBES: UM POSITIVISTA OU UM JUSNATURALISTA?
}

Thadeu Weber ${ }^{1}$

\section{Resumo}

O objetivo fundamental é apresentar Hobbes como um legítimo representante do jusnaturalismo. O argumento principal se dá a partir da explicitação da concepção de liberdade desenvolvida no Leviatã. A admissão de leis naturais, como leis da razão, recoloca o problema da origem do conteúdo e da justificação das leis positivas. A impossibilidade da transferência dos direitos naturais e o preenchimento das lacunas do ordenamento jurídico (silêncio da lei) pelas leis naturais são apresentados como fortes argumentos a favor do jusnaturalismo hobbesiano.

Palavras-chave: jusnaturalismo, positivismo, liberdade, leis naturais, contrato social.

\section{INTRODUÇÃO}

É público e notório o clamor por mais segurança, seja nas relações internas dos Estados, seja nas relações internacionais. Os constantes atentados terroristas estão a exigir urgente aprimoramento dos serviços de inteligência e medidas de impacto para fazer frente à instabilidade vivenciada no contexto contemporâneo. $\mathrm{O}$ que está em jogo é a própria capacidade do Estado em dar conta da finalidade de sua instituição.

Em vista disso, a questão que se impõe é esta: que tipo de marco teórico pode fundamentar tomadas de decisão no campo jurídico-político? O debate entre positivistas e jusnaturalistas já rendeu excelentes resultados no referente aos modelos de justificação. A democracia saiu fortalecida. Os clássicos do pensamento político moderno são indiscutivelmente os que mais contribuíram no lançamento das bases do Estado de Direito.

T. Hobbes, um clássico da teoria geral do Estado e do contratualismo moderno, viveu intensamente os conflitos da guerra civil inglesa de 1642 a 1649. Sua principal obra - o Leviatã - precisa ser situada e interpretada a partir desse contexto. Trata-se de uma justificação do poder absoluto, então reinante em seu país. O diagnóstico de seu tempo e a necessidade de pensar uma atuação do Estado com plenos poderes para dar segurança aos cidadãos foi a alternativa encontrada. Esse diagnóstico nos permite fazer alguma analogia com a situação vivenciada em outros países e em outras épocas, bem como em determinadas relações internacionais. As guerras

\footnotetext{
${ }^{1}$ Professor titular dos Programas de Pós-Graduação de Direito e de Filosofia da Pontifícia Universidade Católica do Rio Grande do Sul.E-mail: weberth@pucrs.br
} 
civis se repetem. A violência desenfreada é um fato. Atentados terroristas são cada vez mais comuns. Escândalos de corrupção ecoam por toda parte. O clamor por segurança é geral e a insatisfação com a atuação do Estado o acompanha.

A difícil questão a ser resolvida refere-se ao tipo de Estado que queremos. Em que bases será legitimado? Quais são seus limites? Inúmeras respostas já foram dadas a estas questões. Liberais e comunitaristas divergem profundamente, sobretudo no que se refere aos limites de atuação do Estado. Positivistas e jusnaturalistas têm pontos de partida distintos para justificar a origem e a função do Estado. Afinal, quem tem razão: a esquerda ou a direita hegeliana? A saída do Reino Unido da União Europeia não representa o fortalecimento do nacionalismo, o Estado-nação hegeliano? As divergências são profundas. Voltar aos clássicos pode trazer importantes contribuições a esse debate.

Motivado pela discussão em torno do jusnaturalismo e/ou positivismo de Hobbes, o intuito é apresentar o referido autor como legítimo representante do jusnaturalismo ${ }^{2}$, contrariando, em parte, a tese de Bobbio que o situa entre os positivistas. ${ }^{3}$ Por que essa discussão é relevante? Porque está em jogo a base de justificação do próprio contrato social. Afinal, a lei positiva deve fundamentar-se na lei natural e tirar dela seu conteúdo ou ela é legitimada pelo pacto e não tem nenhuma relação com a lei natural? Existe uma relação entre moral e direito? Além do mais, o propósito é investigar até que ponto a concepção antropológica hobbesiana é decisiva para justificar uma determinada espécie de governo a ser adotada. Que analogia se pode fazer entre o diagnóstico de Hobbes e o contexto social e político atual? Como ler Hobbes hoje?

\section{A CONCEPÇÃO DE NATUREZA HUMANA}

\section{A igualdade natural e o diagnóstico da insegurança}

Que analogia pode-se estabelecer entre "a condição natural da humanidade", descrita por Hobbes no Leviatã, e o contexto de instabilidade e insegurança que vivenciamos em pleno século XXI? Apesar dos inúmeros contratos e acordos nacionais e internacionais não evoluímos muito na realização dos objetivos que motivaram a criação do Estado: a paz e a segurança.

Há um ponto de partida comum aos contratualistas modernos: Os homens são naturalmente iguais. Não se está falando da igualdade perante a lei, mas no que diz respeito às qualidades físicas e intelectuais. Hegel, apenas para dar um exemplo, é um dos modernos que contesta esta tese. ${ }^{4}$ Sustenta ser a sociedade civil marcada

\footnotetext{
${ }^{2}$ Podemos adotar a definição de jusnaturalismo elaborada por Bobbio. Para ele, jusnaturalistas são "aqueles sistemas de ideias" para as quais "além do direito positivo (...), existe o direito natural" e este é "superior" ao direito positivo (1991 p. 138).

${ }^{3}$ Ver BOBBIO, N. Thomas Hobbes, principalmente capítulo 4.

${ }^{4}$ Ver HEGEL, Grundlinien der Philosophie des Rechts, capítulo sobre a Sociedade civil, principalmente $\$ 200$.
} vol.10, nº. 03, Rio de Janeiro, 2017.pp. 1568-1581 
profundamente pela desigualdade natural, sobretudo pelas habilidades dos indivíduos, condicionados por “circunstâncias contingentes" (HEGEL, 1986, \ 200, p. 353). Hobbes, ao referir-se à "condição natural da humanidade", é categórico: a natureza fez os homens iguais, ou como afirma em Do Cidadão: "Todos os homens são naturalmente iguais entre si” (1992, p. 33), isto tanto no referente às faculdades do corpo quanto às do espírito (cf.1979, p. 74). Santillan acrescenta a "igualdade de direito" (o direito de cada um a todas as coisas) e a "igualdade nas paixões", sobretudo a que se refere à busca pelo poder (Santillan, 1992, p. 21). A confirmação dessa tese vem da nona lei da natureza, assim enunciada no capítulo XV do Leviatã: "Que cada homem reconheça os outros como seus iguais por natureza" (p. 92) $)^{5}$. A consequência direta disso é que da "igualdade quanto à capacidade deriva a igualdade quanto à esperança de atingirmos nossos fins" (1979, p. 74). Os homens têm apetites pelas mesmas coisas que nem sempre podem ser desfrutadas por todos. Essa igualdade quanto à satisfação de expectativas os torna inimigos. Ou seja, a escassez de bens é uma das principais causas de conflitos.

Desse ponto de partida decorre toda uma descrição da situação em que os homens se encontram em sua condição natural, isto é, anterior à celebração de um contrato social ou na ausência de leis capazes de inibir e regular sua conduta. Se Aristóteles acreditava na sociabilidade natural humana e, sobretudo, de que "o homem nasce para a cidadania" (Aristóteles, 1979, p. 55), Hobbes não endossa essa posição. Os homens não são naturalmente sociáveis ${ }^{6}$. Rousseau, para dar um exemplo de outro contratualista, comunga dessa tese, embora por razões diferentes. Para Hobbes, o homem é insociável porque é desconfiado. Para Rousseau o homem é insociável porque é autossuficiente. "Quando não existe um poder capaz de manter a todos em respeito", sustenta Hobbes, "os homens não tiram prazer algum da companhia uns dos outros" (1979, p. 75). Na ausência de um "poder comum" o que os caracteriza é a "luta de todos contra todos"7. Esta é motivada por três causas: a competição, a desconfiança e a vanglória. Pela primeira, o que visamos é o lucro, pela segunda, a segurança e pela terceira, a reputação. Bobbio resume isso dizendo que para Hobbes o que "impulsiona o homem contra o homem é o desejo inesgotável de poder” (Bobbio, 1991, p. 35). Esta tese, aliás, é amplamente desenvolvida em capítulo específico do Leviatã, que pode ser sintetizado na seguinte afirmação do autor: "Assinalo assim, em primeiro lugar, como tendência geral de todos os homens, um perpétuo e irrequieto desejo de poder e mais poder, que cessa apenas com a morte" (1979, p.60). Há que se salientar que, para Hobbes, o desejo de poder é da natureza humana, não sendo, pois, de todo negativa. Tudo depende do uso que dele se faz.

É preciso insistir que ao caracterizar o estado de natureza o autor não está falando de um estado primitivo

\footnotetext{
${ }^{5}$ Sobre a igualdade natural no Estado de Natureza e suas implicações, ver Kersting, 2001, p. 98. Ver, também, Santillan, J. F. 1992, p. 21.

${ }^{6}$ Kersting fala em "déficit de sociabilidade", inscrita na natureza humana. Cf. 2001, p. 93.

${ }^{7}$ Ver caracterização do estado de natureza hobbesiano feita por W. Kersting em Filosofia Política del Contractualismo Moderno, p. 93. Também Leo Straus, The Political Philosophy of Hobbes, cap. VII, p. 108.
} 
ou de uma situação hipotética ${ }^{8}$. Está se referindo ao ser humano tal como ele é e agirá na ausência de leis e do temor do castigo que elas representam. No prefácio da obra Do Cidadão, Hobbes enuncia o que chama de "princípio" conhecido de todos os homens: "As disposições dos homens naturalmente são tais que, a menos que sejam restringidos pelo temor a algum poder coercitivo, todo homem sentirá desconfiança e temor de qualquer outro" (1992, p. 16). Santillan destaca as características imutáveis do ser humano. Ao referir-se ao estado de natureza de Hobbes, sustenta que este "apresenta uma ideia fixa e imutável do ser humano" (1988, p. 112). O risco de cair num determinismo, no entanto, é grande. Qual seria, então, ainda o papel da educação? O absolutismo não será a única alternativa encontrada e justificada? O fato é que, segundo a análise do autor, a concepção de natureza humana determina o papel do Estado. A força das paixões requer a atuação de um poder absoluto, exercido pelo Estado.

De qualquer sorte, a caracterização da condição natural da humanidade hobbesiana é uma tentativa de identificar a causa da situação de insegurança em que se encontra seu Estado e que de alguma forma nos faz pensar sobre nosso contexto social e político. É a incapacidade do Estado em oferecer as garantias constitucionais, que nos leva a buscar no Leviatã de Hobbes possíveis razões que explicam tamanha insegurança. Por vezes, ficamos tentados a pensar que nos encontramos numa condição de "guerra de todos contra todos", uma vez que vivemos um tempo em que o "poder comum" não é capaz de manter a todos em respeito e segurança. A luta pelo poder não tem limites. $\mathrm{O}$ autor acerta ao dizer que a condição de guerra não consiste propriamente numa batalha, mas na situação de instabilidade originada pela ausência das garantias de paz. O problema, hoje, não gira em torno da inexistência de leis, mas na ineficácia de muitas delas, seja por inoperância do Estado brasileiro, por exemplo, em aplicá-las, seja pela ausência do senso de justiça dos cidadãos. Com a ineficiência do poder público, voltamos à "condição natural" de instabilidade política, social e econômica. Não é só a guerra que desestabiliza, mas também a constante disposição para ela. "A competição pela riqueza, a honra, o mando e outros poderes leva à luta, à inimizade e à guerra, porque o caminho seguido pelo competidor para realizar seu desejo consiste em matar, subjugar, suplantar ou repelir o outro" (Hobbes, 1979, p. 60). Para usar a terminologia hobbesiana, o que nos deixa inseguros para viajar de férias, por exemplo, não é a chuva, mas a "tendência" para chover. A instabilidade nos deixa inseguros, seja de que ordem ela for. É, como diz o autor, a "conhecida disposição" para lutar que provoca a instabilidade política e social. Diante disso, não se pretende, em hipótese alguma, justificar um Estado autoritário, ou até mesmo totalitário. A democracia já é uma conquista da história. O que se quer é um Estado constitucional eficiente, com leis claras e eficazes. Certamente apreendemos de Hobbes que "pactos sem a espada não passam de palavras" (Leviatã, 1979, p. 103). Leis sem previsão de punição quando do seu descumprimento, não têm eficácia.

É claro que Hobbes está pensando na guerra civil inglesa e na convulsão social que ela provocou em seu

\footnotetext{
${ }^{8}$ Macpherson discorda e sustenta ser o estado de natureza uma "hipótese lógica, não histórica" (1979, p. 30). Estaria Hobbes vol.10, nº. 03, Rio de Janeiro, 2017.pp. 1568-1581 
país. A analogia com o nosso contexto, no entanto, ocorre ao natural. O que o autor descreve como condição natural (anterior ao Estado ou na condição da ausência das leis ou de sua eficácia no Estado) ou mesmo na guerra civil que viveu em seu país, vive-se também hoje dentro de alguns Estados e em algumas relações internacionais. Não é, pois, uma situação hipotética que o autor está descrevendo, conforme interpretação de Santillán (cf. 1988, p. 111) e de Macpherson (1979, p. 29), mas a situação real de seu país, tal como ocorre de forma análoga hoje em muitos Estados, em guerras civis e mesmo em relações interestatais ${ }^{9}$. Hobbes é um autor rigorosamente realista. Sua concepção de natureza humana certamente tem como motivação inicial a guerra civil de seu país, mas vai muito além disso. Bobbio tem razão ao caracterizar esse estado de natureza hobbesiano como situação de guerra civil, portanto, situação "antiestatal" e como de instabilidade nas relações internacionais, o que chama de "interestatal" (cf. 1991, p. 36). Macpherson diz ser o estado de natureza a "afirmação quanto ao comportamento a que seriam levados os homens (como agora são, indivíduos que vivem em sociedades civilizadas e que tem desejos de homens civilizados) se fosse suspensa a obrigação ao cumprimento de todas as leis e contratos" (1979, p. 33). Daí o caráter hipotético do estado de natureza. Mas Hobbes não está pensando no comportamento dos homens mesmo sem a "suspensão do cumprimento das leis"? Apesar das leis, a insegurança é uma constante.

Qual é a consequência dessa situação de guerra de todos contra todos no diagnóstico de Hobbes? As noções de justiça/injustiça, bem/mal simplesmente não têm lugar. "Onde não há poder comum não há lei, e onde não há lei não há injustiça" (Hobbes, 1979, p. 77). Onde não há pacto social, nada é injusto. Não há injustiça natural, assim como não há bondade ou maldade natural. Não existe critério para defini-lo. Por isso, é inadequado dizer que, para Hobbes, os homens são maus por natureza. O mesmo vale para Rousseau, quando se diz que, segundo ele, os homens são bons por natureza. Os homens não são bons ou maus por natureza. É a lei civil (instituída), mediante o contrato social, que define o que é justo e o que é bom. Nem há distinção entre o legal e o moral; ambos são definidos pelo pacto ou a partir dele. Diferente do que pensava Locke ${ }^{10}$, do ponto de vista do estado de natureza, também não há direito de propriedade. Este direito pode ou não ser instituído pelo contrato social. Pode haver posse, e se houver é contingente, mas não propriedade. Esta só se efetiva com a instituição do Estado. Pode-se perceber que o autor em pauta é o legítimo representante da justiça formal. A justiça consiste na obediência à lei, seja qual for o conteúdo. Mas aonde estaria, então, seu jusnaturalismo? A resposta envolve uma explicitação do conteúdo e do papel das leis naturais.

pensando numa situação de ausência da lei ou na guerra civil de seu país? A segunda alternativa enfraquece a tese de Macpherson.

9 Também Kersting descreve o estado e natureza como "espaço vital fictício do homem natural", como "uma construção metódica", um "experimento mental" (2001, p. 93).

${ }^{10}$ Sobre o direito de propriedade em Locke, ver Segundo Tratado sobre o Governo Civil, capítulo V. 


\section{As leis naturais como leis da razão}

Pela caracterização da condição natural da humanidade fica claro que é pela instituição da lei positiva, com previsão de penalidades, que o Estado poderá ter condições de assegurar a paz entre os homens. "Pactos sem a espada não passam de palavras, sem força para dar qualquer segurança a ninguém” (Hobbes 1979, p. 103). Toda ênfase repousa, pois, sobre as "cadeias artificiais". A tese positivista parece estar claramente configurada. O poder coercitivo das leis é que importa.

O curioso, no entanto, é que, exatamente, no final do capítulo sobre a "condição natural", Hobbes fala em "leis de natureza", afirmando que a "razão sugere adequadas normas de paz" (Hobbes 1979, p. 77). No Do Cidadão ele define lei natural como o "ditame da reta razão no tocante àquelas coisas que, na medida de nossas capacidades, devemos fazer, ou omitir, a fim de assegurar a conservação da vida e das partes de nosso corpo" (p. 45). Bobbio, para minimizar sua importância, as chama de "regras prudenciais" (Bobbio, 1991, p. 38). A posição a ser defendida é no sentido de evidenciar o papel das leis naturais no preenchimento das lacunas do ordenamento jurídico, o silêncio das leis.

A concepção antropológica hobbesiana envolve, pois, duas dimensões fundamentais: $\mathrm{O}$ homem é paixão e razão. Afirma Bobbio: "O homem não é menos um ser de razão do que de paixão" (1991, p. 38). Entre as paixões está a busca desenfreada pelo poder e o domínio sobre os outros; a razão é a capacidade de discernimento para fazer o que se deve para atingir a paz. Paixões e razão estão, pois, em constante conflito. O problema é que desse conflito, na ausência de um poder estatal forte, as primeiras se impõem sobre à segunda.

Mas como se pode, então, considerar Hobbes um legítimo representante da justiça formal se seu sistema jurídico parte da existência de leis naturais? Que poder absoluto é este se o soberano está sujeito às leis de natureza? É preciso salientar que não se trata, obviamente, de leis divinas, mas de "ditames da razão". Independem de contratos sociais. Pela capacidade de cálculo da razão, ou pelo "ato de raciocinar", sabemos o que devemos fazer, mas que não o fazemos dada a força das paixões.

Quais são as leis da razão e qual é o papel delas na teoria política de Hobbes? O autor dedica dois capítulos do Leviatã e vários no Do Cidadão a elas e enumera em torno de vinte. Importam as três primeiras, a título de exemplo.

A primeira, considerada a lei fundamental de natureza, é assim enunciada: "procurar a paz e segui-la" (Hobbes, 1979, p. 78). Ela enuncia a própria finalidade da criação do Estado. Na interpretação de Dieter Hüning, a busca da paz, evidenciada como primeira e fundamental lei natural, "pode ser caracterizada como norma fundamental da filosofia do direito hobbesiana e representa o fundamento da dedução das leis naturais (2011, p. 31). Zelar pela paz é, pois, um “ditame da razão". Cabe a lei civil implementá-la, tornando-a eficaz.

A segunda refere-se à autodefesa e diz: "por todos os meios que pudermos, defendermo-nos a nós vol.10, nº. 03, Rio de Janeiro, 2017.pp. 1568-1581 
mesmos" (Hobbes, 1979, p. 78). Esta lei é a que nos faculta usar de todos os meios possíveis para a preservação de nossa vida. É a base da legítima defesa. Um pacto que permitisse a sua violação seria sempre nulo. É em nome dele que ninguém pode recusar-se a si próprio. É a conclusão lógica da razão.

A terceira diz respeito ao cumprimento dos pactos: "Que os homens cumpram os pactos que celebrarem" (Hobbes, 1979, p. 86). É da própria lógica dos pactos de que as leis sejam cumpridas. É importante insistir que se trata de uma lei da razão e que não pode ser violada por nenhuma lei positiva. Ao contrário, ela é uma garantia para a lei positiva e da eficácia dos pactos em geral. A celebração de pactos pressupõe a disposição do seu cumprimento. Ora, é precisamente nessa lei que está a fonte da justiça. Nada é justo ou injusto senão em função da celebração de um pacto. Em outras palavras, estas noções só têm lugar no momento da instituição do Estado. "Onde não há Estado, nada pode ser injusto" (Hobbes, 1979, p. 86). Não há propriedade onde não houver contrato, pois é este que estabelece o que é meu e o que é teu. Essa lei da natureza, na verdade, ordena que os pactos que vierem a ser celebrados, sejam cumpridos. É mais uma vez o cálculo lógico da razão que está em jogo. No entanto, é fundamental perceber que, embora Hobbes não o admita expressamente, há uma ideia de justiça no próprio cumprimento da lei natural: cumprir o pacto é justo, enquanto lei da razão. Não haveria, então, uma noção de justiça natural, anterior ao pacto?

Uma questão que imediatamente se impõe é esta: Qual é o papel dessas leis da natureza ou leis da razão no projeto político hobbesiano? Dão o conteúdo às leis positivas? Dizem o que é justo ou injusto? Se derem o conteúdo às leis positivas, estamos diante de um jusnaturalismo. ${ }^{11}$ Dizem o que é justo? Certamente não, pois isto é determinado pelos pactos, que são artificiais e não naturais. Pelo que se pode perceber, as respostas a essas questões é que vão definir o jusnaturalismo ou o positivismo hobbesiano.

\section{O CONTRATO SOCIAL}

\section{A finalidade do Estado}

Afinal, porque celebramos pactos e estabelecemos restrições sobre nós mesmos? Que preço estamos dispostos a pagar em troca de segurança? Diferentes autores e correntes comumente concordam num ponto: a finalidade do Estado é garantir a segurança e o bem-estar de seus cidadãos. O desafio, no entanto, é chegar a um acordo sobre suas competências para dar conta desse objetivo.

A segunda parte do Leviatã de Hobbes ocupa-se do Estado. Uma das questões centrais refere-se à sua finalidade. Para ele "é o cuidado com a própria conservação e com uma vida mais satisfeita" (Hobbes, 1979, p. 103). É o desejo de sair do estado de natureza, sem lei, e de luta de todos contra todos, que motiva a criação do

\footnotetext{
${ }^{11}$ Esta é uma questão central a ser retomada mais adiante.
} 
Estado ou a sua manutenção, apesar de suas limitações e insuficiências. O objetivo fundamental é, em última instância, fazer cumprir as leis da natureza, as leis da reta razão. A primeira refere-se, precisamente à paz. O fato é que na ausência do pacto não há garantia de que as leis naturais sejam respeitadas por todos. Elas por si só não têm eficácia.

Questão ainda mais difícil se impõe: que tipo de Estado queremos? Que direitos estamos dispostos a transferir em troca da garantia de segurança e do bem-estar? Os direitos fundamentais podem ser limitados? Que tipo de força e poder o Estado terá de ter para fazer frente às paixões naturais e fazer valer as leis positivas?

Se, por um lado, existe certa concordância sobre a finalidade do Estado, há, por outro, muita divergência no que se refere à concepção própria de Estado e de sua capacidade para atingir aquele objetivo. Entre os contratualistas modernos as divergências já começam com a própria concepção de natureza humana e da concepção antropológica que ela envolve. Basta ver as diferenças entre Hobbes, Locke e Rousseau. ${ }^{12} \mathrm{O}$ fato é que essas divergências foram decisivas na justificação do tipo de contrato social a ser efetivado.

Nesse ponto Hobbes parece ser o mais realista: as paixões naturais são mais fortes do que as leis da natureza. $\mathrm{Na}$ ausência do temor de algum poder comum, capaz de fazer respeitá-las, essas leis não passam de palavras. A justificação de um Estado absoluto deve-se, pois, à concepção do estado de natureza. Somente um Estado com plenos poderes poderá fazer frente ao "homem lobo do homem".

Pode-se discordar do tipo de Estado defendido por Hobbes, mas há que se reconhecer que são fortes os motivos para justificá-lo, dado seu contexto histórico. A insegurança e a instabilidade política, vivida pelo autor e que de certa forma se atualiza, em alguns casos, no contexto contemporâneo, continuam a merecer uma atuação mais firme e estratégica do Estado. Obviamente que não se trata de defender qualquer forma de absolutismo, mas de discutir as próprias bases da democracia e aperfeiçoá-la. Ou, em linguagem contemporânea, no exercício da cidadania, em que consiste propriamente a liberdade política? Se as instituições do próprio Estado são hoje corroídas pela corrupção e pela busca desenfreada da satisfação dos interesses pessoais, como fazer com que o interesse público se sobreponha às paixões naturais ou interesses particulares?

O fato é que a ânsia pelo poder continua alimentado toda e qualquer negociação político-partidária. Como resposta, o exercício do poder político requer regras claras e punições severas para os infratores. Mas estará alguém acima delas? Talvez aí esteja uma das insuficiências de Hobbes: no ímpeto de justificar o Estado em prol da segurança, não considerou suficientemente o fato de o poder ser exercido por homens com as mesmas paixões do estado de natureza ${ }^{13}$. O autor em pauta não desenvolve uma teoria do abuso do poder por parte do príncipe.

\footnotetext{
${ }^{12}$ Ver Santillan, J. F. Hobbes e Rousseau: Entre la autocracia y la Democracía, sobretudo a terceira parte. O autor faz um oportuno estudo comparativo entre Hobbes e Rousseau.

${ }^{13}$ Locke, com clara referência a Hobbes, chamou atenção para o fato de "serem os monarcas absolutos somente homens" (Segundo Tratado Sobre o Governo Civil, p. 38).
} 
Bobbio concorda com essa tese. “Não pode haver abuso onde não há limites” (Bobbio, 1991, p. 51). Isso deve ser entendido no sentido de que ele não faz parte do pacto e, pois, não está sujeito às leis positivas. Ele faz a lei e, claro, com o objetivo de dar segurança. Para Rousseau, por exemplo, a força política está na vontade geral, na soberania popular. Neste caso temos a defesa de uma democracia direta. Em Hobbes os três poderes (executivo, judiciário e legislativo) estão reunidos na mesma pessoa - o soberano.

De qualquer sorte, o contrato social é uma transferência mútua de direitos. O que demarca o critério de distinção do justo e do injusto são as leis civis. A questão é saber o que pode e o que não pode ser transferido por um pacto. A resposta a esta questão vai definir o jusnaturalimo de Hobbes.

\section{A liberdade e o jusnaturalismo}

O enquadramento de Hobbes na corrente jusnaturalista deve ser vinculado à sua concepção de liberdade. A questão central é esta: instituído o Estado e criadas as leis civis, em que consiste a "liberdade dos súditos"? Qual é o limite de atuação dos cidadãos, considerando a quase total transferência de direitos à vontade do poder soberano? Que tipo de recusa é facultado aos "súditos"?

No que diz respeito à liberdade dentro do contrato social e sua vinculação com o jusnaturalismo, três aspectos podem ser referidos:

1. É preciso examinar detalhadamente "quais os direitos que transferimos no momento em que criamos o Estado" (Hobbes, 1979, p. 132). A questão é deveras central e atual. O conhecimento dos direitos e deveres é indispensável para o exercício da liberdade. O claro conhecimento dos termos do Contrato Social é condição para compreensão dos limites da liberdade de ação dos cidadãos. Considerando que as leis são de conhecimento público, os contornos da atuação dos cidadãos estão bem definidos. Não é possível defender um direito de todos a tudo. Mas o que é exatamente objeto de pacto? Consideremos, a título de exemplo, o contexto brasileiro: Até que ponto conhecemos a Constituição de 1988? Quem efetivamente está familiarizado com o Código de Defesa do Consumidor? Quantos brasileiros já leram o Estatuto da Criança e do Adolescente? Quem conhece o conteúdo da "Lei Maria da Penha”? Quais são efetivamente nossos direitos e deveres como cidadãos? Como reivindicar liberdade sem o conhecimento de seus limites? Afirma Hobbes: "o conhecimento da lei civil é de caráter geral e compete a todos os homens" (Hobbes, 1979, p. 161). Essas questões envolvem a definição do âmbito da liberdade dentro de um pacto. Em Hobbes, o objeto de pacto é a segurança. A transferência de direitos visa atender esta finalidade.

2. A segunda questão é mais direta quanto ao papel das leis de natureza. Todo cidadão ou súdito "tem a liberdade em todas aquelas coisas cujo direito não pode ser transferido por um pacto" (Hobbes 1979, p. 
133). E o que não pode ser transferido? Tudo o que se refere às leis naturais, originárias da razão. Algumas situações são clássicas e sempre atuais: se alguém for interrogado sobre um crime que cometeu, não pode ser obrigado a confessá-lo, "porque ninguém [...] pode ser obrigado por um pacto a recusar-se a si próprio" (Hobbes, 1979, p. 133 e 1992, p. 57). É a segunda lei da natureza - a autodefesa - que assegura isso. Há, portanto, liberdade para se valer de todos os meios para preservar a autodefesa. É o que alegamos quando asseguramos que ninguém pode ser obrigado a produzir prova contra si próprio. A própria legítima defesa se enquadra nisso. A autodefesa é a base do direito de permanecer em silêncio. Estamos, pois, diante de uma clara orientação, dada pelas leis da razão, para a celebração de pactos justos. Nesse caso, a lei natural (lei da razão) fundamenta a lei positiva.

Situação mais enigmática diz respeito à pena de morte. É possível justificá-la, considerando, por um lado, o poder absoluto do Soberano e, por outro, a segunda lei da natureza? A resposta é positiva. Todavia, autorizar a pena de morte não significa abrir mão da autodefesa ${ }^{14}$. É isso que autoriza o réu a permanecer em silêncio. $\mathrm{O}$ ônus da prova cabe a quem acusa. Em nome da lei de natureza podemos fazer uso de todos os meios possíveis para defender-nos. Na condição de legislador (direta ou indiretamente) posso permitir que me matem se vier a cometer determinado crime, mas isso não me obriga a confessá-lo e muito menos que não me defenderei ou que recuse a mim próprio. A lei positiva (pena de morte) não pode violar os ditames da reta razão. E a lei da reta razão não proíbe a pena de morte, mas a violação da autodefesa. Isso de alguma forma significa que as leis de natureza dão o conteúdo às leis positivas. Um positivista jamais admitiria tal hipótese. Ora, esse jusnaturalismo hobbesisno indica que o exercício do poder não é absoluto.

3. O silêncio das leis.

Para todos os casos em que não houver previsão legal o cidadão tem liberdade "de fazer ou omitir" (Hobbes, 1979, p.134). Em termos de Constituição brasileira, trata-se do dispositivo constitucional segundo o qual "ninguém será obrigado a fazer ou deixar de fazer alguma coisa senão em virtude de lei" (Artigo 5o , inciso II). Esta, por si só, é uma afirmação essencialmente positiva. Mas quando não há lei, tudo é permitido? Não voltaríamos, com isso, ao estado de natureza? Exatamente aí, no silêncio da lei, ou para usar uma expressão de Bobbio, "nas lacunas do ordenamento jurídico" (Bobbio, 1991, p. 116), vigoram as leis da razão ${ }^{15}$. Não é possível fazer lei para tudo e nem necessário. As leis da razão têm exatamente aí seu papel: preencher as lacunas da lei positiva. É claro em Hobbes o soberano é a lei. Mas não está acima das leis de natureza. Onde as leis positivas silenciam vigoram as leis naturais, as leis da razão. "As leis naturais são obrigatórias em todos os casos onde as leis positivas silenciarem”, resume Bobbio (1991, p. 116). Só por essa afirmação ele não poderia ter concluído pelo

\footnotetext{
${ }^{14}$ Sobre o tema da pena de morte, em Hobbes, ver Ao Leitor sem Medo, Renato J. Ribeiro, p. 88. Ver também Do Cidadão, p. 56.
} vol.10, no. 03, Rio de Janeiro, 2017.pp. 1568-1581 
positivismo hobbesiano.

Uma analogia pode ser feita com a distinção de Dworkin entre regras e princípios: sobretudo nos hard cases, quando não há previsão legal ou quando a validade das leis é duvidosa recorra-se aos princípios, que também são normativos, embora possam não ser leis naturais. Cabe ao juiz julgar, nos casos não previstos em lei, de acordo com as leis da razão ou de acordo com os princípios do direito costumeiro. É a ele que cabe a interpretação da lei. Exagera Bobbio ao afirmar que em Hobbes "há uma característica geral das leis naturais que diminui seu vigor: elas obrigam apenas em consciência" (Bobbio, 1991, p. 110). Para o jusnaturalismo esta obrigação é incondicional. É claro que, para Hobbes, sem o castigo da lei positiva as leis naturais não têm eficácia. Mas é preciso reconhecer que as leis positivas não podem violar o conteúdo das leis da razão. Teríamos, então, uma matéria constituída de forma prévia à lei positiva? Para um positivista não. Mas Hobbes refere as leis da razão como anteriores à celebração do pacto ou como independentes dele e, pois, anteriores à criação das leis civis, as "cadeias artificiais". Mas também diz que aquelas são ineficazes sem estas. Mas ser ineficaz não significa não ter validade. Ou seja, as leis positivas tornam eficazes as leis de natureza, através do estabelecimento do temor do castigo. Por isso, Bobbio considera Hobbes um "positivista por inclinação mental e por raciocínio, mas jusnaturalista por necessidade" (Bobbio, 1991, p. 125). Ora, isto é contraditório. O silêncio das leis, no entanto, continua sendo o ponto central do jusnaturalismo de Hobbes. O preenchimento dessas lacunas, bem como o fornecimento do conteúdo das leis positivas, cabe às leis da razão. A necessidade das leis positivas para eficácia das leis naturais não anula o valor destas para o fornecimento do conteúdo do contrato social.

E o comportamento do soberano em relação às leis naturais? A resposta é direta: ele deve respeitá-las. Donde se conclui que seu poder não é absoluto.

\section{CONSIDERAÇÕES FINAIS: O JUSNATURALISMO HOBBESIANO}

Embora esse tema já tenha sido ventilado com a discussão sobre a liberdade, convém insistir em alguns pontos que efetivamente permitem caracterizar a teoria política hobbesisna de jusnaturalista.

Embora, por si mesmas, as leis de natureza possam não ter eficácia, elas indicam a matéria às leis civis. Se o objetivo maior do Estado é dar garantias de segurança e de paz, e o faz através das leis civis, na verdade não está introduzindo um conteúdo novo com o contrato social. Está apenas, e isso não é pouco, operacionalizando as leis da razão. É esta que enuncia o objetivo maior do Estado. Sabemos o que devemos fazer (pelas leis da razão) para tornar a convivência possível, só não o fazemos em virtude da força das nossas paixões. Estas não são em si negativas, pois, negativo é o seu uso indevido. Se nossa tendência é primeiro atender nossos interesses pessoais, é preciso estabelecer limites para sua efetivação, tendo em vista o interesse público. As leis civis têm essa função.

${ }^{15}$ Sobre a liberdade dos súditos e o silêncio das leis, ver Ao Leitor sem Medo, Renato J. Ribeiro, p. 87. vol.10, no. 03, Rio de Janeiro, 2017.pp. 1568-1581 
Se o contrato social é uma transferência de direitos, fica muito claro nos textos de Hobbes que esta transferência não é ilimitada. E o limite é dado precisamente pelas leis de natureza ou ditames da reta razão. $\mathrm{O}$ direito de autodefesa é o exemplo mais convincente e atual. Ninguém pode, mesmo em nome da segurança e da paz, ser obrigado a recusar-se a si próprio. Pode-se até concordar com a introdução da pena de morte em casos especificamente definidos, mas isso não fere a lei de natureza. Não estou autorizando, com isso, que não me defenderei usando de todos os meios possíveis. Autorizar a pena de morte não significa abrir mão do direito de autodefesa. Não se pode negar ao soberano o direito de condenação, conferido pelo pacto, mas se pode resistir fazendo uso de todos os meios possíveis, inclusive o uso da força. O Estado tem, pois, nas leis naturais, seu limite de ação. Mas como qualificar Hobbes como representante da justiça formal se o conteúdo da lei civil é dado pelas leis da razão? Há que se salientar que a ênfase do autor está na eficácia das leis positivas, dada pela sua penalização. Em vista disso, as noções de justo e injusto estão vinculadas às "cadeias artificiais".

Observa-se que a lei da razão é o limite da lei civil. Esta encontra sua justificação naquela. Dizer que as leis naturais "obrigam apenas em consciência”, como faz Bobbio, não lhes retira o mérito de fornecer o conteúdo às leis positivas. Dizer que obrigam apenas em consciência, não significa dizer que não obrigam. Alguém pode respeitar as leis da razão sem o temor do castigo imposto pela lei positiva. É claro que Hobbes não acreditaria nesta possibilidade, dada sua concepção de natureza humana e da força das paixões. Considerando que as leis naturais só seriam eficazes com a introdução das leis civis, Bobbio conclui pelo positivismo hobbesiano "por inclinação e por raciocínio" (Hobbes, 1979, p. 125). Para um jusnaturalista, no entanto, é a lei positiva que se conforma à lei natural e não o contrário. E é isso que ocorre no Leviatã. A impossibilidade de transferência das leis da reta razão no ato da criação do Estado é uma prova disso. $\mathrm{O}$ argumento do silêncio da lei reforça essa tese. Em linguagem contemporânea, poder-se-ia dizer que nos hard casesé aos princípios, escritos ou não, que se deve recorrer. Estes não são extra-legais, como sustentam os positivistas, tais como Hart e Kelsen ${ }^{16}$. É claro que isso não significa dizer que sejam leis naturais, mas certamente são normas do direito costumeiro.

Argumento importante que reforça o jusnaturalismo hobbesiano diz respeito à duração da obediência por parte do cidadão. No Leviatã, o autor afirma categoricamente que "o fim da obediência é a proteção" (Hobbes, 1979, p.135). Ora, a pergunta que logicamente se impõe, então, é esta: e se o Estado, no caso o poder soberano, não oferecer garantias de segurança? A resposta reforça o peso dos direitos que os homens têm por natureza. O pacto dura enquanto durar a capacidade de proteção. "O direito que por natureza os homens têm de defenderem-se a si mesmos não pode ser abandonado através de pacto algum” (Hobbes, 1979, p. 135). A criação do Estado é produto de um cálculo racional: obediência=proteção. Cessando esta, cessa aquela. $\mathrm{O}$ direito de autodefesa é anterior ao pacto e por isso não pode ser abandonado por este. A rigor, esse direito não depende do

\footnotetext{
${ }^{16}$ Ver Teoria Pura do Direito de Kelsen, principalmente primeiro capítulo.
} 
Estado. Somente recorremos a ele (ao Estado) para sua garantia. Em não havendo esta, voltamos ao estado natural, onde cada um usará de seu poder para assegurá-lo. Afirma Janine Ribeiro, comentando o Leviatã de Hobbes, a propósito do assunto da proteção: "Até a incompetência administrativa, atestada, por exemplo, no trato inepto de uma revolta ou de uma fome catastrófica, absolverá os súditos de sua obrigação, se não mais tiverem a vida protegida ou preservada pelo Estado" (Ribeiro, 1984, p. 112). São, pois, claros os indícios, de já, em Hobbes, encontrarmos elementos de justificação da desobediência civil. A ineficiência do Estado leva os cidadãos a se defenderem por si próprios buscando serviços de segurança particulares ou até fazendo justiça pelas próprias mãos. É a volta ao estado de natureza, sem lei.

\title{
HOBBES: A POSITIVIST OR A NATURALIST?
}

\begin{abstract}
In this paper, we argue that Hobbes is a legitimate representative of legal naturalism. The main argument is brought forth by explaining the concept of freedom laid out in Leviathan. The admission of natural laws, such as the law of reason, poses the problem of the origin of the content and of the justification of positive laws. We present the impossibility of transferring natural laws and the filling of gaps in the legal order (silence of the law) by natural laws as strong arguments for Hobbesian legal naturalism.
\end{abstract}

Keywords: legal naturalism, positivism, freedom, natural laws, social contract.

\section{REFERENCIAS}

ARISTÓTELES. Ética a Nicomaco. São Paulo: Abril Cultural, Os Pensadores, 1979.

BOBBIO, N. Thomas Hobbes. Rio de Janeiro: Editora Campus, 1991.

HEGEL, G. F. W. Grundlinien der Philosophie des Rechts. Frankfurt am Main: Suhrkamp, 1986.

HOBBES, T. Leviatã. São Paulo: Abril Cultural, Os Pensadores, 1979.

Do Cidadão. São Paulo: Martins Fontes, 1992.

HÜNING, Dieter. "Inter arma silent leges" ("Entre as armas as leis se calam"). Direito Natural, Estado e o Direito das Gentes em Thomas Hobbes. In: Hobbes: natureza, história e política. Marcelo G. Villanova / Wladimir B. Lisboa (org). Vol. II, POA/Cordoba: Edipucrs e Editoral Brujas, 2011.

KELSEN, Hans. Teoria Pura do Direito. São Paulo: Matias Fontes, 2003.

KERSTING, Wolfgang. Filosofia Política del Contractualismo Moderno. Mexico: Plaza y Valdés, S. A. 
LOCKE, J. Segundo Tratado Sobre o Governo Civil. São Paulo: Abril Cultural, 1978.

MACPHERSON, C.B. A Teoria Política do Individualismo Possessivo. Rio de Janeiro: Paz e Terra, 1979.

RIBEIRO, R. J.Ao Leitor sem Medo: Hobbes escrevendo contra seu tempo. São Paulo: Brasiliense, 1984.

SANTILANN, J. F. Hobbes y Rousseau: Entre la autocracia y la democracia. México: Fondo de Cultura Económica, 1988.

STRAUSS, Leo. The Political Philosophy of Hobbes. Chicago: University of Chicago Press, 1963.

Trabalho enviado em 06 de setembro de 2016.

Aceito em 17 de abril de 2017. 